\title{
Structure of the Mate-Killer (mu) particles in Paramecium aurelia, stock 540
}

\author{
By G. H. BEALE AND A. JURAND \\ Department of Animal Genetics, University of Edinburgh, Scotland
}

(Received 16 March 1960)

\begin{abstract}
SUMMARY
The mate-killer (mu) particles in the cytoplasm of Paramecium aurelia, stock 540, variety (syngen) 1, were studied by: Feulgen-staining; phase-contrast microscopy; fluorescence under ultraviolet irradiation after staining with acridine orange; electron microscopy (including the 'silver-Feulgen' technique). The appearance of the particles following treatment with DNAase and RNAase was observed. It was found that the mu particles were capsulated rod-shaped structures, 2-10 $\mu$ long and about $0 \cdot 3 \mu$ in diameter (excluding the capsule); they appeared to reproduce by transverse fission without formation of cross-walls. There was an external double membrane and the internal material consisted largely of DNA, which was not limited to particular zones but spread throughout the interior of the particle. RNA was also present. The relationships of the particles to other micro-organisms is discussed, and it is concluded that they do not differ from bacteria in any important respect.
\end{abstract}

\section{INTRODUCTION}

Ever since the discovery of the 'killer' strains of Paramecium aurelia by Sonneborn (1938) there has been discussion about the nature and homologies of the cytoplasmic kappa particles responsible for the peculiar killing properties of these paramecia. At one time kappa particles were considered to be gene-like elements in the cytoplasm or plasmagenes (Sonneborn, 1947), but this view became less plausible as knowledge of the particles increased. For example Preer (1948) showed that they could be stained and seen with the light microscope, and were as large as some bacteria. Moreover, Sonneborn (1948) showed that at least one kind of kappa particle could be experimentally transmitted from one paramecium to another by infection through the external medium. These and other findings strengthened the belief, which had been firmly held all along by certain critics (e.g. Altenburg, 1946), that the particles were to be regarded as symbiotic micro-organisms rather than plasmagenes. Their exact position remains, however, uncertain, as can be seen from the discussion of Preer \& Stark (1953) and the recent exhaustive review of Sonneborn (1959).

Characterization of a micro-organism would ideally require a thorough description of both morphological and physiological properties, but since kappa and similar particles cannot as yet be grown anywhere except within the cytoplasm of a paramecium, we are restricted to morphological and cytochemical studies. In this paper we give an account of the structure of one type of cytoplasmic particle called mu, 
occurring in Paramecium aurelia, stock 540 (variety or syngen 1). This stock was originally collected in Mexico, and was kindly made available to us by DrT.M. Sonneborn. It is a mate-killer having the same general properties as the mate-killers earlier described by Siegel (1953) in variety 8. As found there, when conjugation between a mate-killer and a normal (sensitive) organism takes place, nuclear exchange proceeds normally, but one half of the ex-conjugants (those which receive cytoplasm from the sensitive conjugant) die after two fissions or less, whilst the other half (which receive cytoplasm, and hence mu particles, from the mate-killer conjugant) give rise to fully viable clones. The mechanism causing the death of the sensitive organisms is unknown, but it has been shown by Siegel (1954) that contact of the surfaces of mate-killer and sensitive paramecia for a minimum of about $2 \mathrm{hr}$. is required. Exchange of the internal contents, either nuclei or cytoplasm, is not an essential part of the killing process. A brief account of the stock 540 mate-killer, including some genetical information, was given previously (Beale, 1957). Out of 60 stocks of $P$. aurelia variety 1 collected from many different parts of the world; stock $\mathbf{5 4 0}$ is the only mate-killer.

\section{METHODS}

Cultures. The paramecia were grown on baked lettuce or dried grass infusions containing Aerobacter aerogenes. Abundant mu particles were obtained by allowing the cultures of paramecia to starve for 3-4 days at room temperature in dilute buffered saline. Under such conditions the particles continue to multiply whilst the paramecia do not. The ciliates were concentrated by drawing the culture fluid through a Berkefeld candle, and subsequent centrifugation of the organisms from the fluid which remained behind.

Light microscopy. The fixatives most commonly used were methanol + acetic acid $(3: 1)$, and $1 \%(w / v)$ osmic acid buffered to $\mathrm{pH} \mathrm{7 \cdot 2}$. Time of fixation was $1 \mathrm{hr}$. For Feulgen staining the material was hydrolysed with $\mathrm{N}-\mathrm{HCl}$ for $5 \mathrm{~min}$. at $60^{\circ}$, and stained for $1 \frac{1}{2} \mathrm{hr}$. (whole mounts) or $2 \frac{1}{2} \mathrm{hr}$. (sections) at room temperature in dilute buffered saline. Azure A staining (see DeLamater, 1951) was by a procedure essentially the same as for the Feulgen procedure, except that in place of Feulgen reagent, staining was with azure $A$ for $3-4 \mathrm{hr}$. at room temperature. Paraffin sections were cut at 2-7 $\mu$ thickness.

Preparations of mu particles for phase-contrast observations were made by gently crushing a few living paramecia on a slide with a coverglass and observing the particles directly (method of Preer \& Stark, 1953).

For the demonstration of translucent capsules surrounding the particles, a method based on that described by Duguid (1951) was used. A dense suspension of paramecia was crushed between a slide and coverslip. The coverslip was then removed and placed on a drop of water on a clean slide. Indian ink was infiltrated into the preparation and the particles which adhered to the coverslip were observed by phase-contrast microscopy, with an oil-immersion objective.

Fluorescence of particles stained with acridine-orange was studied by a technique based on that described by Anderson, Armstrong \& Niven (1959). The particles on a slide were washed with $0.01 \mathrm{~m}$-acetate buffer ( $\mathrm{pH} 5$ ), stained for $2 \mathrm{hr}$. with acridine orange (2.5 mg. in $1 \mathrm{ml}$. of the same buffer), thoroughly washed with buffer, and examined under ultraviolet (u.v.) radiation under the microscope with a dark ground 
condenser (Zeiss). An Osram high-pressure mercury vapour lamp (type HBO 200) was used as source of u.v. radiation.

Electron microscopy. The preferred fixative was $1 \%(\mathrm{w} / \mathrm{v})$ osmic acid, buffered to $\mathrm{pH} 7 \cdot 2$ with veronal +acetate at $1 / 9$ the concentration recommended by Palade (1952). For special purposes methanol + acetic acid (3:1) was also used as fixative. The time of fixation was $1 \mathrm{hr}$. at room temperature, after which the suspensions of whole paramecia were dehydrated, embedded in methacrylate and sectioned at about 250 A. on a Porter-Blum Servall microtome. A Siemens Elmiscope I electron microscope was used.

Enzyme treatments. (a) DNAase. After fixation of whole paramecia with osmic acid or methanol + acetic acid and thorough rinsing in water and buffer (0.003 $\mathrm{M}$-tris buffer at $\mathrm{pH} 7 \cdot 6 ; 0.02 \mathrm{M}-\mathrm{MgSO}_{4} .7 \mathrm{H}_{2} \mathrm{O}$ ), the suspensions of organisms were divided into two parts (tris buffer, even though it causes considerable distortion, was used in place of phosphate buffer here since a precipitate formed when the latter is used with the DNAase preparation containing $\left.\mathrm{MgSO}_{4}\right)$. One part was treated with a solution of crystalline DNAase (Nutritional Biochemicals Corp.; $1 \mathrm{mg} . / 10 \mathrm{ml}$. buffer) for $2 \mathrm{hr}$. at $37 \cdot 5^{\circ}$. The second part was left in buffer for the same time and at the same temperature, as a control. Following DNAase treatment samples were stained by the Feulgen method and examined in the light microscope to check the effectiveness of the digestion; the remainder were prepared for electron microscopy as described above.

(b) RNAase. After fixation with methanol +acetic acid (3:1) and thorough rinsing in 1/10 Ringer solution buffered to $\mathrm{pH} 6.8$ with $0.004 \mathrm{M}$-phosphate, the suspensions of whole paramecia were treated with a $1 \%(\mathrm{w} / \mathrm{v})$ solution of crystalline RNAase (Light) for $3 \mathrm{hr}$. at $37^{\circ}$. Effectiveness of the digestion was checked by staining samples by the methyl-green pyronin method, and observing with the light microscope the absence of pyronin-stained material in the cytoplasm.

'Silver-Feulgen' method (based on a technique of Bradfield, 1954; see also Jurand, Deutsch \& Dunn, 1959). After osmic fixation for $1 \mathrm{hr}$. and hydrolysis in $\mathrm{N}-\mathrm{HCl}$ at $60^{\circ}$ for $5 \mathrm{~min}$. the material was washed with distilled water until no reaction took place with a $3 \%(\mathrm{w} / \mathrm{v}) \mathrm{AgNO}_{3}$ solution, then treated for $1-3 \mathrm{hr}$. at $40-48^{\circ}$ with a $1.5 \%(\mathrm{w} / \mathrm{v})$ aqueous solution of hexamethylenetetramine containing $0.25 \%(\mathrm{w} / \mathrm{v})$ $\mathrm{AgNO}_{3}$ buffered with borate to $\mathrm{pH} 8 \cdot 3$. The paramecia were then washed in $1.5 \%$ $(\mathrm{w} / \mathrm{v})$ hexamethylenetetramine, rinsed with water, then with $5 \%(w / v)$ sodium thiosulphate and again with water. The material was then dehydrated and embedded in methacrylate.

\section{RESULTS}

\section{Light microscope observations}

Feulgen and azure- $A$ staining. In mounts of whole paramecia the mu particles appeared as clouds of stained material (PI. 1, fig. 2a); usually individual particles could not be distinguished. When the paramecia were sectioned, the individual particles were seen more clearly ( $\mathrm{Pl}$. 1, fig. 1) and were then revealed as Feulgenpositive rod-shaped structures, with no internal differentiation. After 3-4 days starvation of the paramecia, the particles were extremely numerous and occupied almost the entire cytoplasm. With less severe starvation of the paramecia the particles were aggregated in one or two large colonies, in a manner similar to that 
described previously by Siegel (1954) for the mu particles in other stocks. Following DNAase treatment of mate-killer paramecia, no Feulgen-positive material remained in the cytoplasm, nor, of course, in the nucleus (Pl. 1, fig. 2b). (The darker material in Pl. 1 , fig. $2 b$, is due to browning produced by osmic acid, not to the Feulgen reaction.)

Phase-contrast observations. The mu particles were not seen inside living unstained paramecia, but when the latter were gently crushed, causing the contents to flow out, the particles became easily visible in phase contrast, as previously recorded for the kappa particles in other stocks by Preer \& Stark (1953). Stock 540 mu particles became characteristically orientated flat on the glass slide (Pl. 1, fig. $3 a$ ), and were not washed off with distilled water or culture fluid, nor were they removed when the coverslip was taken off, the fluid allowed to dry and the preparation re-wetted. Some of the particles likewise adhered to the coverslip. These treatments left the particles adhering to the glass surface, and it was therefore possible to obtain a homogeneous preparation of mu particles since most other cytoplasmic structures were washed away with water. Solutions of higher ionic strength $(2 \%, w / v$, $\mathrm{NaCl}$ or $\mathrm{N}-\mathrm{HCl}$ ) caused the particles to become detached from the glass. As seen in phase contrast, the particles were usually about $2 \mu$ in length, but varied between 2 and $10 \mu$. A constriction was frequently seen, but no internal structural details were discerned. The refractile bodies described by Preer \& Stark (1953) in kappa particles were not present in the mu particles. It will be noticed in Pl. 1, fig. $3 a$, that the particles never appear to come into direct contact with one another, and this is a general rule. Even after DNAase treatment, which removed all Feulgen-positive material (this constitutes the bulk of the internal contents of the particles; see below) the appearance of the latter in phase contrast remained unchanged; and the same was found after RNAase treatment. The particles therefore possess a rigid envelope made of some substance other than nucleic acid. The presence of translucent material or capsules surrounding the particles was clearly shown by the indian ink technique (see $\mathrm{Pl}$. 1, fig. $3 b$ ). Considerable variation in the thickness of the capsule was found in different particles, but it was commonly about $0 \cdot 2 \mu$ thick.

Fluorescence following acridine-orange staining. Cells of higher organisms, and also bacteria, when stained with acridine orange at particular $\mathrm{pH}$ values and examined under u.v. radiation, show differential fluorescence of DNA- and RNAcontaining regions (see Anderson et al. 1959). For example these authors report that, at pH 5, RNA fluoresced red and DNA green or greenish yellow in the bacteria Salmonella typhi and Escherichia coli.

Preparations of unfixed and of methanol + acetic acid fixed mu particles on glass slides obtained by crushing the paramecia were stained with acridine orange and examined under u.v. radiation. The fluorescence of the mu particles was always weak, notwithstanding use of longer and stronger staining procedures than those recommended by Anderson et al. For comparison we sometimes included in the same preparations bacteria (Aerobacter aerogenes) and cytoplasm and nuclei of Paramecium, and found that these fluoresced brightly as expected.

At pH 5 the mu particles fluoresced a pale yellowish colour. When they had been pretreated with DNAase and then stained with acridine orange, fluorescence was somewhat more orange, and when the pretreatment was with RNAase, the 
fluorescence became more greenish, than in the preparations not treated with enzymes. It is therefore concluded that the particles contained RNA and DNA, but the reason for the faintness of the fluorescence is not known. In any case no internal differentiation of RNA- and DNA-containing regions was demonstrated by this method.

\section{Electron microscope observations}

Ultra-thin sections of mu particles in the cytoplasm of osmic acid-fixed paramecia, as seen with the electron microscope, are shown in Pl. 1 and 2, figs. 4-8. The particles are seen to be bounded by a double membrane, have a diameter of about $0 \cdot 3 \mu$, are usually quite straight, and contain material which appears more dense than the cytoplasm of the paramecia. Within the dense material there is an arrangement of irregular vacuole-like areas, within which dense granules are frequently seen. Sometimes a section was obtained which showed a rather regular row of these 'vacuoles', each one containing a dense central spot, but usually the pale regions were irregularly distributed and might be close against the external membrane. A single large vacuole was often found at one end of a particle (Pl. 2, fig. 8). In particles which showed a median constriction, and were apparently about to undergo transverse fission, no internal cross-wall was seen ( $\mathrm{Pl}$. 1, fig. 4). Around the outside of the particles a pale area was commonly (though not always) found, corresponding to the capsule as seen in phase contrast by the indian ink technique (see especially Pl. 1, fig. 6). (Mitochondria and other cytoplasmic inclusions showed no such surrounding pale area.) Where the particles were concentrated in one or two large groups in the cytoplasm, the latter appeared generally less dense in that region than where there were few or no particles. A number of normal paramecia (not mate-killers) were sectioned and examined in the electron microscope; none was found to contain the mu particles as described above.

Effect of enzyme treatment on appearance of particles in the electron microscope. In Pl. 3, figs. $9 b$ and $10 b$, are shown preparations of paramecia treated with DNAase before embedding and sectioning. Pl. 3, fig. 10, shows material fixed with osmic acid (and washed with tris buffer) and Pl. 3, fig. 9, material fixed with methanol+ acetic acid (and washed with phosphate buffer). In each case samples of DNAasetreated material were stained by the Feulgen method and confirmation was obtained that all Feulgen-positive material had been removed from the mu particles and from the macronucleus. Further, DNAase-treated material was stained with pyronin; it gave positive reactions. Thus it was confirmed that DNAase treatment removed DNA but not RNA, and that the fixatives used did not interfere with subsequent digestion by DNAase.

The DNAase-treated material was compared with controls which were treated according to the same procedure of fixation, washing in buffer, etc., but not treated with enzyme (Pl. 3, figs. 9a, 10a). This was important since the appearance of the particles in the electron microscope was markedly affected by such treatments, as can be seen by comparison of Pl. 3, figs. $9 a, 10 a$ with Pl. 1, figs. 4-6. We have never considered it worth while to make comparisons between preparations made at different times, since there is no doubt that slight variations in the kind of buffer, times and temperatures of washing, etc., have profound effects on the appearance of the material in the electron microscope. The effect of the DNAase treatment was 
clearly to remove the greater part of the electron-dense material from both osmicacid-fixed and methanol + acetic-acid-fixed $\mathrm{mu}$ particles. Some electron-dense material remained round the outer margin and a few irregular granules within. In the methanol + acetic acid-fixed preparations, the contents of the particles were shrunken away from the membrane; DNAase treatment resulted in some swelling (Pl. 3, figs. 9b, 10b). From these observations it is concluded that most of the electron-dense material inside the particles contained DNA, which was not restricted to any central 'nuclear' region.

The effects of treatment with the RNAase preparation were also studied, and were quite clear in spite of the severe distortion brought about by the methanol + acetic acid fixation and rinsing in Ringer solution, etc. (see Pl. 4, fig. 13a). RNAase treatment resulted in the disappearance of the pale vacuole-like regions, so that the particles became uniformly opaque (Pl. 4, fig. 13b). A superficial resemblance may be noted between the particles in Pl. 4, fig. $13 b$ (RNAase treated), and Pl. 3, fig. $9 a$ (controls for DNAase experiment), but this is due to the fact that in Pl. 3, fig. 9a, the pale areas in the particles were much decreased in size on account of the tris buffer used. It is tentatively concluded that RNA is present in the 'pale' regions, and that the structure of the latter is destroyed by RNAase, allowing the electrondense material to flow in. It is not excluded, of course, that RNA is present also in the electron-dense regions before treatment with RNAase.

'Silver-Feulgen' reaction. As described in the 'Methods' section, some mate-killer paramecia were hydrolysed with $\mathrm{N}-\mathrm{HCl}$ and impregnated with silver nitrate. The idea behind this method is that products of hydrolysis of DNA (aldehydes), which re-colorize Schiff's reagent in the normal Feulgen technique, would also be expected to reduce silver nitrate to metallic silver, which could then be detected in the electron microscope. Some paramecia were therefore hydrolysed and impregnated with silver nitrate, then embedded, sectioned and observed in the electron microscope. The mu particles in these preparations were found to contain a massive electrondense deposit-('silver granules'), especially in a zone just inside the outer double membrane, and to a lesser degree in the interior of the particles ( $\mathrm{Pl}$. 4, fig. 11). Other cytoplasmic structures such as mitochondria showed no such concentration though there was a background of electron-dense granules randomly distributed throughout (though much less dense than in the mu particles). The macronucleus, as expected, showed a dense accumulation of electron-dense granules. Unhydrolysed material when treated with silver nitrate in the same way showed no differential accumulation of silver granules in the mu particles or elsewhere, but merely a random deposition. That reduction of silver to the metallic form was in fact brought about by the hydrolysis products of DNA was shown by studying the effect of DNAase on preparations subsequently treated with silver nitrate. Pl. 4, figs. $12 a$, $12 b$, shows a comparison of DNAase-treated and control particles, and clearly reveals an almost complete absence of silver granules in the enzyme-treated particles, in spite of severe distortion of the structure of the particles due to the various chemical treatments. 


\section{DISCUSSION}

From these observations it is concluded that the mu particles in Paramecium aurelia stock 540 (mate-killer) are rod-shaped structures varying in length between 2 and $10 \mu$, width about $0 \cdot 3 \mu$, and surrounded by a double membrane and capsule. In a general way they resemble the kappa particles of other stocks of $\boldsymbol{P}$. aurelia described by Dippell (1958) and Hamilton \& Gettner (1958), but there are differences in detail. The mu particles studied here differ from the kappa particles by being longer and thinner, in lacking the refractile bodies found in a proportion of kappa particles (so-called 'brights'), and in the presence of a capsule. The kappa particles are more or less uniformly distributed throughout the cytoplasm whilst the mu particles form large clusters; it seems likely that this clumping is connected with the presence of the capsular material, since it will be remembered that the cytoplasm of paramecia is a fluid medium constantly circulating in the living organisms. The mu particles, like kappa particles, contain DNA and this substance is not confined within central 'nuclear' bodies, but spread throughout the particles. RNA is also present, as also reported for kappa by Dippell $(1959 a, b)$.

The mu particles resemble certain bacilli in size and shape and it is with these organisms that we should compare the particles most closely. The most striking difference is in the localization of the 'nuclear' material. With many bacteria, even though no chromosomes can be seen, the 'nuclei' are localized in a definite zone in the centre of the cell, containing Feulgen-positive material. In electron micrographs. this zone appears less dense than the rest of the bacterial contents, but within this less dense zone extremely electron-dense material may sometimes be seen and the latter has been considered to be identical with the Feulgen-positive material seen in the light microscope (Maaløe \& Birch-Andersen, 1956). These workers consider that in bacteria fixed with osmic acid or formaldehyde aggregates of DNA are objects which appear dark in electron micrographs. This would be in conformance with the results of our studies on the effect of treatment of the mu particles with DNAase, which led to a considerable decrease or elimination of electron-dense material within the particles in both osmic acid and methanol + acetic-acid-fixed material. What is unusual about the contents of the mu particles is that the DNAcontaining material seems to occupy practically the whole of the interior of the particle, extending even to the external double membrane.

Concerning the 'silver-Feulgen' technique, several different interpretations are possible (as indeed is true also of the classical Feulgen reaction itself). We have found that some structures in paramecia which are unlikely to contain DNA, e.g. parts of the pellicle, may also cause a reduction to metallic silver in hydrolysed material. However, our results with DNAase treatment showed that the silver deposit within the mu particles was in fact due to the presence within them of DNA hydrolysis products. The fact that so high a density of silver granules was found just within the outer double membrane is not clearly understood but we assume is due to the reduction of silver ion immediately on entering the particle, so that a concentration gradient is set up. It seems unlikely that there is localization of DNA around the outside of the particles.

Doubtless objections could be raised against the various interpretations of individual cytochemical reactions which are described here, and particularly 
with regard to enzyme treatments of material examined by electron microscopy. However, when the results of all the tests are considered, a consistent picture is obtained. All the different techniques studied (Feulgen staining; fluorescence of acridine-orange-stained particles; DNAase treatment of particles observed in the electron microscope; the 'silver-Feulgen' technique) have given the same result, namely that the DNA in the particles is spread throughout them. This kind of distribution is not typical of many bacteria which have been examined cytochemically (as earlier noted by Preer \& Stark, 1953). Nevertheless, it is known that the appearance of bacterial 'nuclei' is much affected by the nutritional and ionic conditions before and during fixation and staining (Robinow, 1956), and the habitat of the mu and kappa particles is after all very different from that of the saprophytic bacteria normally studied. The mu particles also differ from many bacteria in their structure during division. Sections of dividing bacteria often show a cross-wall developing between the two halves (see for example Bradfield, 1956); in the constricted mu particles, which one assumes are in the process of fission, no such crosswalls were seen. However, this distinction is unlikely to be critical and many bacteria may well be found to divide by constriction rather than transverse septum formation. Finally, the mu particles apparently lack the cytoplasmic membrane, distinct from the cell wall, often seen in electron micrographs of bacteria.

Whether the mu (and kappa) particles should be classified amongst the bacteria depends entirely on what definition is placed on that group. Doubtless the obligatory intracellular habitat of the particles has led to a nutritional situation where it is unnecessary for them to maintain the metabolic machinery of free-living forms. They would not require many of the enzymes located in the 'cytoplasm' of bacteria, and this might result in a greater proportion of the structure being occupied by nuclear material (as pointed out by Sonneborn, 1959). We therefore conclude that the mu particles are bacteria which have become adapted to life in the cytoplasm of paramecia.

We wish to thank Dr K. Deutsch for his collaboration with electron microscopy during the early stages of this work; also Drs T. M. Sonneborn and J. P. Duguid for criticism of the manuscript, and the last mentioned for drawing our attention to the indian ink technique. One of us (A. J.) is a Research Worker of the British Empire Cancer Campaign.

\section{REFERENCES}

Altenburg, E. (1946). The symbiont theory in explanation of the apparent cytoplasmic inheritance in Paramecium. Amer. Nat. 80, 661.

Anderson, E. S., Armstrong, J. A. \& Niven, J. S. F. (1959). Fluorescence microscopy: observation of virus growth with amidoacridines. In Virus Growth and Variation. Symp. Soc. gen. Microbiol. 9, 224.

Beale, G. H. (1957). A mate-killing strain of Paramecium aurelia, variety 1, from Mexico. Proc. R. phys. Soc. Edinb. 26, 11.

Bradfield, J. R. G. (1954). Electron microscope observations on bacterial nuclei. Nature, Lond. 173, 184.

Bradfield, J. R. G. (1956). Organization of bacterial cytoplasm. In Bacterial Anatomy. Symp. Soc. gen. Microbiol. 6, 296.

DeLamater, E. D. (1951). A new cytological basis for bacterial genetics. Cold Spr. Harb. Symp. quant. Biol. 16, 381. 
Drppels, R. V. (1958). The fine structure of kappa in killer stock 51 of Paramecium aurelia. J. biophys. biochem. Cytol. 4, 125.

DipPELl, R. V. (1959a). Cytological observations on kappa in killer stock 51 of Paramecium aurelia. Anat. Rec. 134, 554 (abstract).

Dippela, R. V. $(1959 b)$. The distribution of DNA in kappa particles of Paramecium in relation to the problem of their bacterial affinities. Science, 130, 1415 (abstract).

Duguid, J. P. (1951). The demonstration of bacterial capsules and slime. J. Path. Bact. $63,673$.

Hamilton, L. D. \& Getrner, M. E. (1958). Fine structure of kappa in Paramecium aurelia. J. biophys. biochem. Cytol. 4, 122.

Jurand, A., Deutsch, K. \& Dunn, A. E. G. (1959). Application of the silver-Feulgen reaction in electron microscopy. J. R. micr. Soc. 78, 46.

MAAløe, O. \& Birch-Andersen, A. (1956). On the organization of the 'nuclear material' in Salmonella typhimurium. In Bacterial Anatomy. Symp. Soc. gen. Microbiol. 6, 261.

Palade, G. E. (1952). A study of fixation for electron microscopy. J. exp. Med. $100,641$.

Preer, J. R. (1948). The killer cytoplasmic factor kappa. Its rate of reproduction, the number of particles per cell, and its size. Amer. Nat. 82, 35.

Preer, J. R. \& Stark, P. (1953). Cytological observations on the cytoplasmic factor 'kappa' in Paramecium aurelia. Exp. Cell Res. 5, 478.

Robinow, C. F. (1956). The chromatinic bodies of bacteria. Bact. Rev. 20, 207.

SigGel, R. W. (1953). A genetic analysis of the mate-killer trait in Paramecium aurelia, variety 8 . Genetics, 38,550 .

Siegel, R. W. (1954). Mate killing in Paramecium aurelia, variety 8. Physiol. Zoöl. $27,89$.

Sonneborn, T. M. (1938). Mating types, toxic interactions and heredity in Paramecium aurelia. Science, 88, 503.

Sonneborn, T. M. (1947). Recent advances in the genetics of Paramecium and Euplotes. Advanc. Genet. 1, 263.

Sonneborn, T. M. (1948). Symposium on plasmagenes, genes and characters in Paramecium aurelia. Amer. Nat. 82, 26.

Sonneborn, T. M. (1959). Kappa and related particles in Paramecium. Advanc. Virus Res. 6, 229.

\section{EXPLANATION OF PLATES}

Figs. 1-3. Light microscope preparations. Figs. 4-13. Electron microscope preparations. $m u$, mu particles; $m a$, macronucleus; $f v$, food vacuole; cap, capsule.

\section{Plate 1}

Fig. 1. Paraffin section of $P$. aurelia, stock 540 mate-killer, fixed with osmic acid, hydrolysed with $\mathrm{N}-\mathrm{HCl}$, stained with azure $\mathbf{A}$, examined in phase contrast.

Fig. $2 a$. Whole mount, fixed and stained as in fig. 1.

Fig. 2b. As fig $2 a$, but treated with DNAase before applying stain. The osmic acid causes some browning (dark in photograph), but the organism is completely unstained.

Fig. 3a. Unstained mu particles outside paramecium, flat on glass slide, observed in phase contrast. Note separation of particles.

Fig. 3b. Unstained mu particles lying flat on coverslip (or hanging vertically). Mounted in indian ink to show capsules. The indian ink particles are in Brownian movement, and produce grey background due to $10 \mathrm{sec}$. exposure of photographic plate.

Fig. 4. EM section through a mu particle, fixed with osmic acid, showing constriction.

Fig. 5. Longitudinal section through a long mu particle.

Fig. 6. Group of mu particles showing capsules in EM. 


\section{Plate 2}

Fig. 7. Comparison of mu particle with bacteria (Aerobacter aerogenes) in food vacuole. Note pale ('nuclear') areas in the bacteria are more concentrated towards the centre than corresponding areas in the mu particles.

Fig. 8. Mu particle with capsule, compared with mitochondria.

Plate 3

Fig. 9a. Mu particles fixed with methanol + acetic acid, treated with tris buffer. Control for fig. $9 b$.

Fig. $9 b$. As fig. 9a, but treated with DNAase.

Fig. 10a. As figs. $9 a$ and $9 b$, but fixed with osmic acid instead of methanol + acetic acid.

Fig. 10b. As fig. 10a, but treated with DNAase.

\section{Plate 4}

Fig. 11. Mu particle prepared by 'silver Feulgen' technique.

Fig. 12a. Mu particles fixed with osmic acid, hydrolysed with $\mathrm{N}-\mathrm{HCl}$ and silvered. Control for fig. $12 b$.

Fig. 12b. As fig. $12 a$, but treated with DNAase before silvering.

Fig. 13a. Mu particles fixed with methanol + acetic acid, rinsed in dilute buffered Ringer solution. Control for fig. $13 b$.

Fig. 13b. As fig. 13a, but treated with RNAase. 

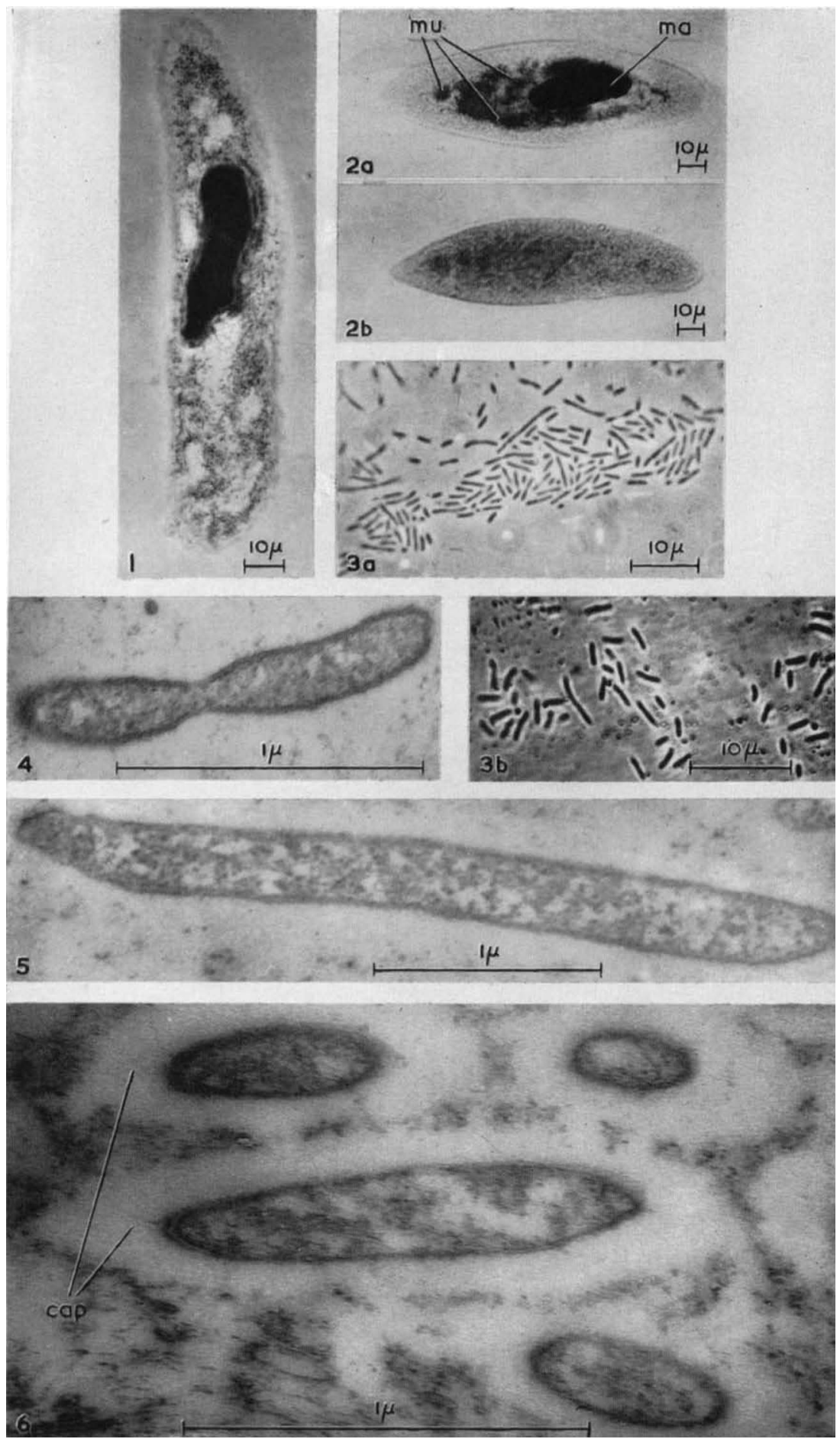

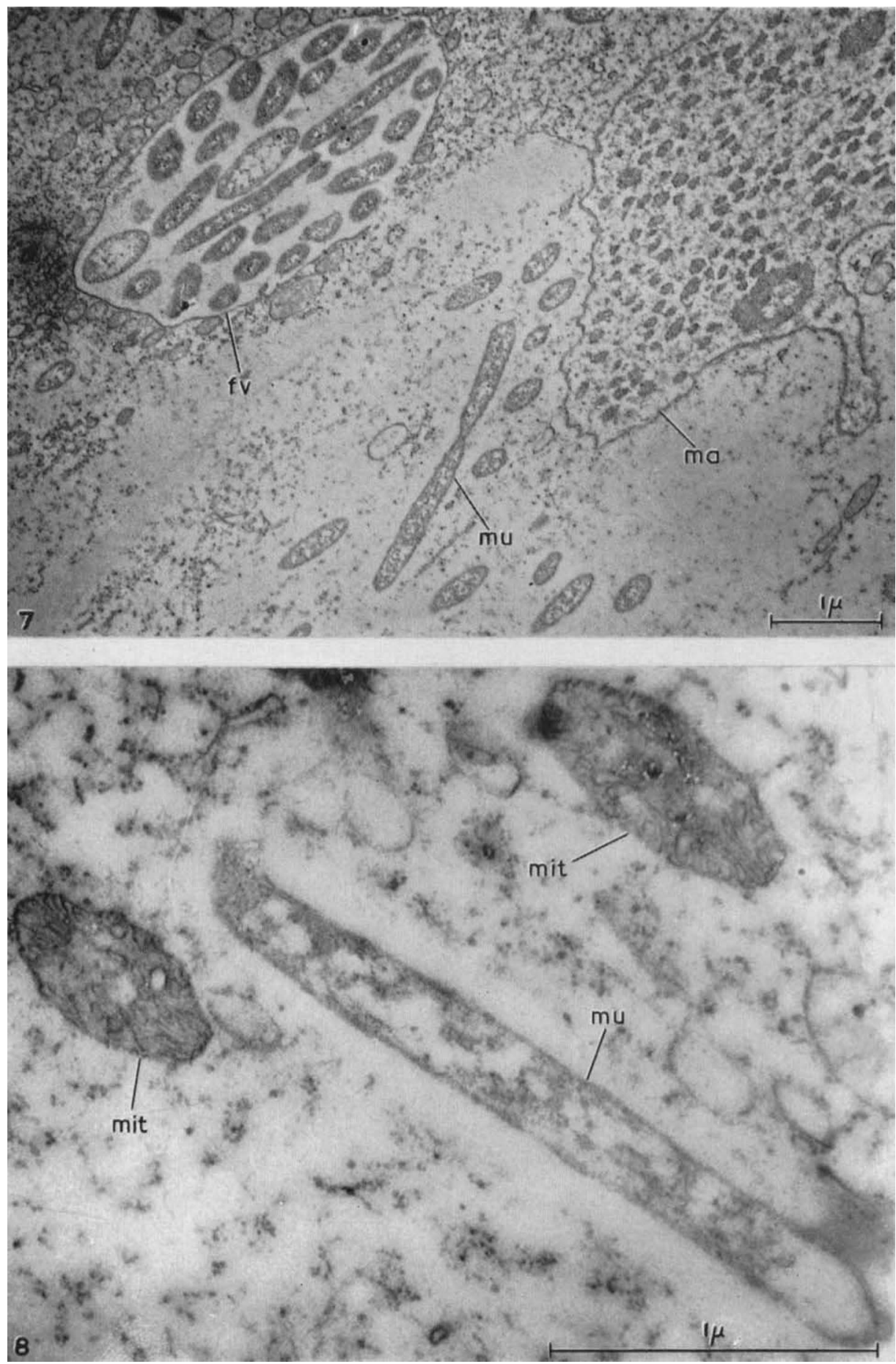

G. H. BEALE AND A. JURAND 

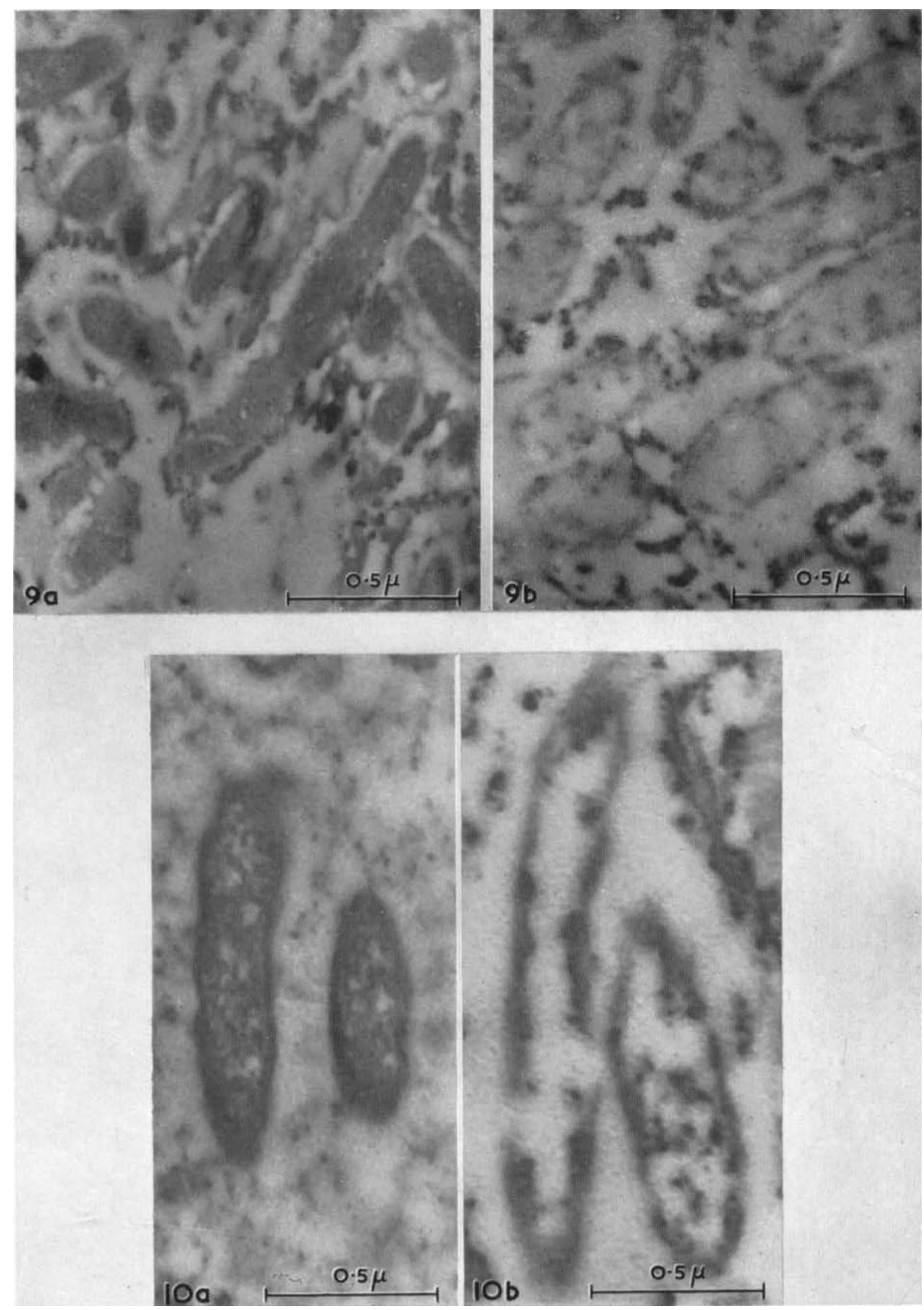

G. H. BEALE AND A. JURAND 
Journat of General Microbiology, Vol. 23, No. 2

Plate 4

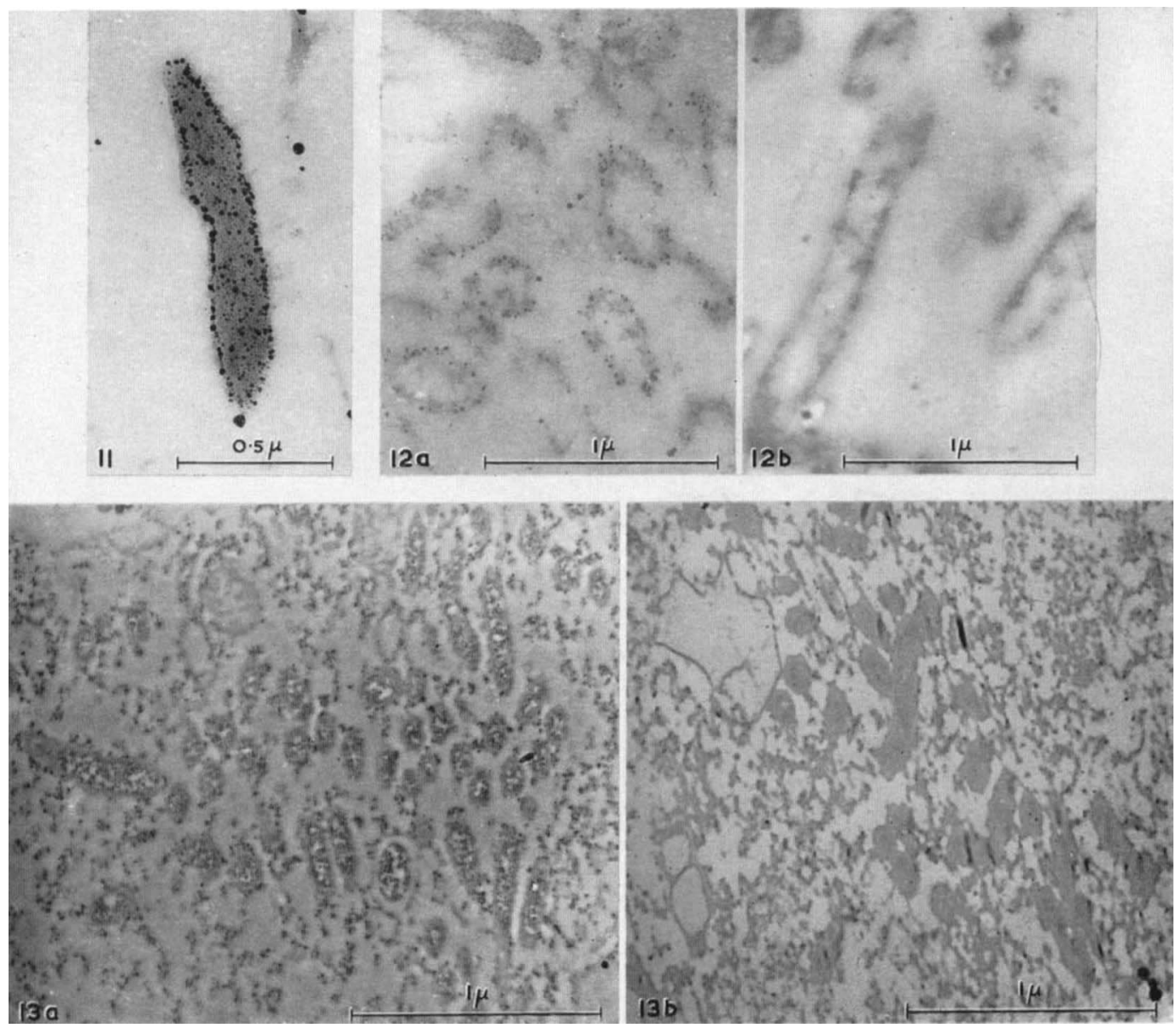

